\title{
$H$ pylori colocalises with MUC5AC in the human stomach
}

G R Van den Brink, K M A J Tytgat, R W M Van der Hulst, C M Van der Loos, A W C Einerhand, H A Büller, J Dekker

\begin{abstract}
Background-The bacterium Helicobacter pylori is able to adhere to and to colonise the human gastric epithelium, yet the primary gene product responsible as a receptor for its adherence has not been identified.

Aims-To investigate the expression of the gastric mucins MUC5AC and MUC6 in the gastric epithelium in relation to $H$ pylori colonisation in order to examine their possible roles in the binding of $H$ pylori.
\end{abstract}

Patients-Seventy two consecutive patients suspected of having $H$ pylori infection.

Methods-MUC5AC, MUC6, and $H$ pylori were detected in single sections of antral biopsy specimens using immunohistochemical triple staining.

Results-MUC5AC was expressed in the superficial epithelium and the upper part of the gastric pits. MUC6 expression was detected in the lower part of the gastric pits. The expression of both mucins in the epithelium was complementary. In each patient, there was a sharply delineated transition between MUC5AC and MUC6 producing cell populations. In all $\mathrm{H}$ pylori positive patients there was a striking colocalisation of $\mathrm{H}$ pylori and MUC5AC; more than $99 \%$ of the bacteria were associated with either extracellular MUC5AC or the apical domain of MUC5AC producing cells.

Conclusions-H pylori is very closely associated with extracellular MUC5AC and epithelial cells that produce MUC5AC. This indicates that MUC5AC, but not MUC6, plays a role in the adhesion of $\boldsymbol{H}$ pylori to the gastric mucosa. (Gut 2000;46:601-607)

Keywords: Helicobacter pylori; gastric mucin; MUC5AC; MUC6; stomach

Pediatric

Gastroenterology,

Erasmus University and Sophia Children's

Hospital, Rotterdam,

The Netherlands

A W C Einerhand

H A Büller

J Dekker

Correspondence to: Dr J Dekker, Lab. Pediatrics, Room Ee 1571A, Erasmus University, Dr

Molewaterplein 50, 3015 GE Rotterdam, The Netherlands

Accepted for publication 3 November 1999 with peptic ulcer disease, ${ }^{3}$ atrophic gastritis, gastric adenocarcinoma, ${ }^{45}$ and gastric MALT lymphoma. ${ }^{6} H$ pylori does not invade the gastric mucosa, but resides in the gastric mucus layer of the superficial epithelium, and can attach to gastric epithelial cells, with a preference for the intercellular junctions. ${ }^{7}$ In in vitro experiments, the attachment to the epithelial cells has been shown to induce signal transduction in gastric cells, with activation of the transcription factor NF- $\kappa B^{8-11}$ Subsequently, the cytokine interleukin 8 (an important $\mathrm{T}$ cell and neutrophil chemoattractant, and critical mediator in the $H$ pylori induced inflammatory process) is produced. Thus, physical contact of the bacterium with the epithelial cell plays a pivotal role in the outcome of infection. ${ }^{12}$ It seems likely that homing to the mucus layer and attachment to mucosal cells are separate processes and may be mediated by different bacterial adhesins and host receptors.

An interesting example of this exists in colonisation of the intestine by another Gram negative bacterium, the enteropathogenic Escherichia coli. This bacterium uses its pili to bind specifically to intestinal mucin in various models, ${ }^{13-15}$ possibly accounting for its colonisation pattern. The bacterial membrane protein intimin and a receptor, Hp90, on the intestinal cell however mediate intimate adhesion to the intestinal cells. It has recently been shown that this receptor is not of host cell origin but actually encoded by the bacterium and translocated into the mammalian cell membrane, ${ }^{16}$ and has thus been renamed Tir (for translocated intimin receptor). This intimin-Tir adhesion can of course not account for its tissue specificity. Thus, separate interactions are involved in the tropism of this $E$ coli for the intestine, and adherence to the intestinal cells. This provides yet another instructive example of the multimolecular nature of enteropathogen-host cell interactions.

$H$ pylori resides only in an ecological niche of mucus produced by gastric epithelium, so the putative receptor has to be specific for gastric mucus. Interestingly, it was shown that $H$ pylori is able to bind to gastric mucin in vitro. ${ }^{17}$ Mucin is the most important structural component of the mucus gel layer. ${ }^{18}{ }^{19}$ These highly $O$-glycosylated molecules form hydrated multimeric complexes. To date, nine human epithelial mucin genes have been identified and designated MUC1-4, MUC5B, MUC5AC, and MUC6-8. ${ }^{19}$ Most of these genes are expressed in a cell type and tissue specific manner. ${ }^{20-26}$ Several of these mucins show a tissue specific regional distribution along the cephalocaudal axis of the gastrointestinal mucosa. On the other hand some of these, particular MUC1

Abbreviations used in this paper: HGM, human gastric mucin. 
and $M U C 4$, are expressed in most regions of the gastrointestinal tract. MUC7 is only expressed in the salivary glands, ${ }^{20}$ MUC5B is also expressed in the salivary glands and is the predominant mucin in the gallbladder, ${ }^{21}$ and MUC2 and MUC3 are expressed in the intestine. ${ }^{22}{ }^{23}$ The secretory mucins MUC5AC and MUC6 are expressed in the epithelium of the stomach. The superficial epithelium and the cells in the upper part of the gastric pits produce MUC5AC. ${ }^{24}{ }^{25}$ MUC6 expression is confined to the lower mucous neck cells and the cells of the antral glands. ${ }^{24-26}$

As $H$ pylori binds gastric mucin in vitro and seems to reside in the mucus layer overlaying the MUC5AC producing cells of the superficial epithelium, we sought to determine a possible colocalisation of MUC5AC and $H$ pylori in the human stomach. Furthermore, we were interested to determine whether the presence of the bacterium would alter the expression pattern of the gastric mucins, MUC5AC and MUC6.

\section{Materials and methods}

PATIENTS

Gastroduodenoscopy was performed on 72 consecutive patients referred to the endoscopy unit of the Academic Medical Center in Amsterdam for chronic upper abdominal complaints. These patients were enrolled in a prospective study investigating the prevalence of $H$ pylori infection in patients on antacid therapy, which was approved by the Ethics Committee of the Academic Medical Center. Biopsy specimens were taken from the antrum of the stomach as part of these investigations. Specimens were fixed in phosphate buffered saline (PBS) buffered paraformaldehyde, and embedded in paraffin. $H$ pylori status was determined by culturing the bacteria, and confirmed by an independent pathologist using routine histology (haematoxylin and eosin (H\&E) stain). The histological grade of gastritis was scored according to the Sydney classification. ${ }^{27}$

\section{ANTIBODIES}

To detect MUC5AC, we used either the mouse monoclonal antibody 45M1 (Novocastra, Newcastle-upon-Tyne, UK), ${ }^{28}$ rabbit polyclonal antihuman gastric mucin (anti-HGM), ${ }^{29}$ or mouse monoclonal CLH2 kindly provided by C A Reis. ${ }^{30}$ To detect MUC6, we used MUC6.1, a polyclonal antibody raised in rabbit, ${ }^{26}$ kindly provided by $\mathrm{C}$ de Bolós. For MUC2 detection, WE9, a monoclonal antibody against MUC2, ${ }^{31}$ raised in mouse was used, a kind gift of D K Podolsky. M3P, a polyclonal antibody against MUC3, ${ }^{23}$ was generously provided by Y S Kim. For staining of $H$ pylori we used either a rabbit polyclonal antibody (DAKO, Glostrup, Denmark) or pooled serum from seven $H$ pylori immunised rabbits, a gift of B Appelmelk. ${ }^{32}$

IMMUNOHISTOCHEMISTRY

To detect MUC5AC, MUC6, and H pylori in a single section, for optimal investigation of their possible colocalisation, an immunohisto- chemical triple staining method was developed. Paraffin sections $(6 \mu \mathrm{m})$ were deparaffinated. Endogenous peroxidase was blocked using $1.5 \% \mathrm{H}_{2} \mathrm{O}_{2}$ in PBS for 30 minutes at room temperature, and washed in PBS. Sections were heated for 10 minutes at $100^{\circ} \mathrm{C}$ in $0.01 \mathrm{M}$ sodium citrate $\mathrm{pH} 6.0$ to enhance antigen retrieval. After cooling on ice for 15 minutes and washing in PBS, sections were blocked in TENG-T (10 mM Tris, $5 \mathrm{mM}$ EDTA, $0.15 \mathrm{M}$ $\mathrm{NaCl}, 0.25 \%$ gelatin, $0.05 \%$ (vol/vol) Tween$20, \mathrm{pH} 8.0$ ) at room temperature. After washing in PBS, the rabbit anti-MUC6 polyclonal antiserum (MUC6.1) was applied (1/200 dilution), and incubated overnight at $4^{\circ} \mathrm{C}$. Thereafter, sections were washed in PBS, incubated with a secondary biotinylated antibody (goat antirabbit Ig/BIO, DAKO) in a $1 / 500$ dilution for one hour at room temperature, and washed in PBS. Sections were incubated with ABcomplex (Vector Laboratories, Burlingame, California) for one hour at room temperature, and washed with PBS. Enzyme activity was detected with diaminobenzidine (DAB, Sigma, St Louis, Missouri), $5 \mathrm{mg}$ of DAB, and $10 \mu \mathrm{l}$ of $30 \% \mathrm{H}_{2} \mathrm{O}_{2}$, in $10 \mathrm{ml} 50 \mathrm{mM}$ Tris $\mathrm{pH} 7.8$, resulting in a brown colour.

Subsequently samples were heated at 90$100^{\circ} \mathrm{C}$ in $10 \mathrm{mM}$ sodium citrate for five minutes and after cooling, blocked with TENG-T, and washed in PBS. Sections were incubated overnight at $4^{\circ} \mathrm{C}$, with a mixture of mouse anti-MUC5AC (45M1) and rabbit anti- $H$ pylori antibodies in $1 / 50$ and $1 / 5000$ dilutions, respectively. On the third day, sections were washed in PBS, and incubated with a mixture of two secondary antisera, one labelled with alkaline phosphatase and the other biotinylated, at room temperature for one hour (goat antirabbit Ig/AP, and goat antimouse $\mathrm{Ig} / \mathrm{BIO}$ in $1 / 20$ and $1 / 100$ dilutions respectively, DAKO). After washing in PBS, sections were incubated for 30 minutes in streptavidin $\beta$ galactosidase (strep $\beta$-gal, Boehringer Mannheim, Mannheim Germany), diluted 1/40 in PBS at room temperature. The strep $\beta$-gal was detected using $1 \% \mathrm{X}$-gal (DAKO) in iron phosphate buffer $(0.02 \%$ $\mathrm{MgCl}_{2} .6 \mathrm{H}_{2} \mathrm{O}, 0.099 \%$ potassium ferricyanide, $0.127 \%$ potassium ferrocyanide) at $37^{\circ} \mathrm{C}$ for 15-30 minutes, resulting in a blue/turquoise colour. After washing in Tris buffered saline, the alkaline phosphatase was detected using the Fast Red detection method (DAKO), staining $H$ pylori a reddish purple. Sections were briefly counterstained with haematoxylin, and mounted in Ultramount (DAKO), an aqueous mounting medium. Two investigators (GRvdB, KMAJT) scored the sections independently in a blinded manner. The distribution patterns of MUC5AC and MUC6 were assessed, and the sections were evaluated for the presence of $H$ pylori, and when present, the percentage of bacteria associated with MUC5AC or MUC6 producing cells was scored.

IMMUNOHISTOCHEMICAL CONTROLS

Controls included staining of normal human gastric tissue sections with antibodies against 
MUC2 and MUC3, and staining of normal human duodenum sections with anti-MUC2, anti-MUC3, anti-MUC5AC, and anti-MUC6. This showed that anti-MUC5AC and antiMUC6 reacted specifically with gastric mucins, whereas anti-MUC2 and anti-MUC3 reacted exclusively with duodenal epithelium, but not with gastric epithelium. Also, when each of the primary or secondary antibodies were omitted no immunoreactivity was observed with any of the detection methods.

\section{Results}

PATIENT CHARACTERISTICS

The 72 endoscopic procedures were performed in 64 patients; eight patients underwent endoscopy twice, for evaluation of eradication treatment. Four of these eight patients were successfully treated. Of the 72 biopsy specimens studied, 34 were from $H$ pylori positive patients, four after failed eradication treatment. Thirty eight biopsy specimens were from $H$ pylori negative patients (19 after successful eradication therapy). The presence of $\mathrm{H}$ pylori was independently assessed by both culturing the bacterium and by a pathologist. We were able to detect the bacterium by immunohistochemistry in all infected patients, and thus the concordance with the independent pathologist and the microbiological detection method was $100 \%$. The severity of gastritis was scored according to the Sydney classification (table 1).

\section{MUCIN EXPRESSION PATTERNS}

In each patient, we examined the expression patterns of MUC5AC and MUC6, and their relation to $H$ pylori colonisation of the gastric mucus layer. We were able to visualise the entire pit-gland axis in the antral mucosa of each patient. Single sections were stained for MUC5AC, MUC6, and $H$ pylori using an immunohistochemical triple staining method. Virtually all epithelial cells of the superficial epithelium and the antral glands express mucin, either MUC5AC or MUC6.

The expression of MUC5AC was localised to cells of the superficial epithelium of the stomach and the upper parts of the gastric glands (fig $1 \mathrm{~A}-\mathrm{F}$ ). In separate experiments we found that these cells were detected by each of the antibodies used to detect MUC5AC (data not shown). The anti-HGM antiserum and the monoclonal antibody $45 \mathrm{M} 1$, which both recognise the MUC5AC precursor as well as the mature MUC5AC molecules, ${ }^{28} 29$ gave near indistinguishable results, staining the intracellular storage granules as well as the secreted mucin (shown in fig 1 for $45 \mathrm{M} 1$ ). Based on the immunohistochemical staining of consecutive

Table 1 Number of patients in each category according to the Sydney classification

\begin{tabular}{lllll}
\hline Activity & $\begin{array}{l}\text { Chronicity } \\
\text { Normal }\end{array}$ & Mild & Moderate & Severe \\
\hline Normal & 19 & 14 & $4 / 1$ & \\
Focal & & $1 / 1$ & 6 & 2 \\
Mild & & 1 & 6 & 5 \\
Moderate & & & 2 & 5 \\
Severe & & &
\end{tabular}

H pylori positive patients are denoted in italics. antrum sections of many patients, it appeared that the monoclonal antibody CLH2 only stained the perinuclear region of MUC5AC expressing cells (data not shown). This was in accordance with the fact that CLH2 is only able to recognise the MUC5AC precursor. ${ }^{30}$ As $45 \mathrm{M} 1$ was able to stain intracellular as well as extracellular MUC5AC we chose to use this antibody in our triple labelling experiments. Using $45 \mathrm{M} 1$, the distribution of MUC5AC staining among the epithelial cells appeared uniform and continuous in all examined biopsy specimens, and this basic expression pattern was not affected in $H$ pylori infected patients (compare fig $1 \mathrm{~A}$ and $\mathrm{C}$ with $\mathrm{D}-\mathrm{F}$ ).

The anti-MUC6 antibody showed strong perinuclear reactivity in the cells of the lower parts of the antral glands (fig $1 \mathrm{~A}-\mathrm{F}, \mathrm{H}-\mathrm{J}$ ). This antibody is able to recognise the MUC6 precursor, explaining the perinuclear staining. ${ }^{26}$ We did not observe reactivity of the anti-MUC6 antiserum with cells of the superficial epithelium or upper part of the glands in any of the biopsy specimens. We found complementary expression of MUC5AC and MUC6 in each patient, but virtually no colocalisation of both mucins (fig 1). The area of transition between MUC5AC and MUC6 producing cells was always sharply delineated (fig $1 \mathrm{~A}-\mathrm{F}, \mathrm{I}$ ).

In many $H$ pylori positive patients we noted a considerable decrease in the number of MUC5AC expressing cells, concomitant with a seeming increase in MUC6 producing cells (compare, for example, fig 1C and D). This apparent shift in number of MUC5AC and MUC6 expressing cells did however not correlate with any change in staining intensity or with the continuity of the staining patterns of either mucin.

\section{H PYLORI LOCALISATION}

Using the triple staining method, we were able to study the relation between mucin expression in the stomach and $H$ pylori colonisation. We found a striking colocalisation of $H$ pylori with MUC5AC in each of the patients infected with the bacterium (fig 1E-I). In all biopsy material, more than $99 \%$ of the bacteria were associated with extracellular MUC5AC, or closely associated with MUC5AC producing cells (fig 1E-I). We never detected more than $1 \%$ of $H$ pylori associated with the MUC6 producing cells in the gastric glands. If bacteria were detected in the proximity of MUC6 producing cells, this was always in the area of transition between MUC5AC and MUC6 producing cells (fig 1I). In most sections we observed dense colonisation by $H$ pylori of the MUC5AC producing epithelium, with a uniform distribution until the margins of MUC5AC containing mucus (fig $1 \mathrm{E}, \mathrm{F}, \mathrm{I}$ ). The bacterium abruptly disappeared at the area of transition to MUC6 expression. In two of the sections examined some of the bacteria were detected in a transected gastric pit containing MUC6 only (data not shown). Although this was very rarely observed, it provided an essential positive control for the ability to detect the purple stained 

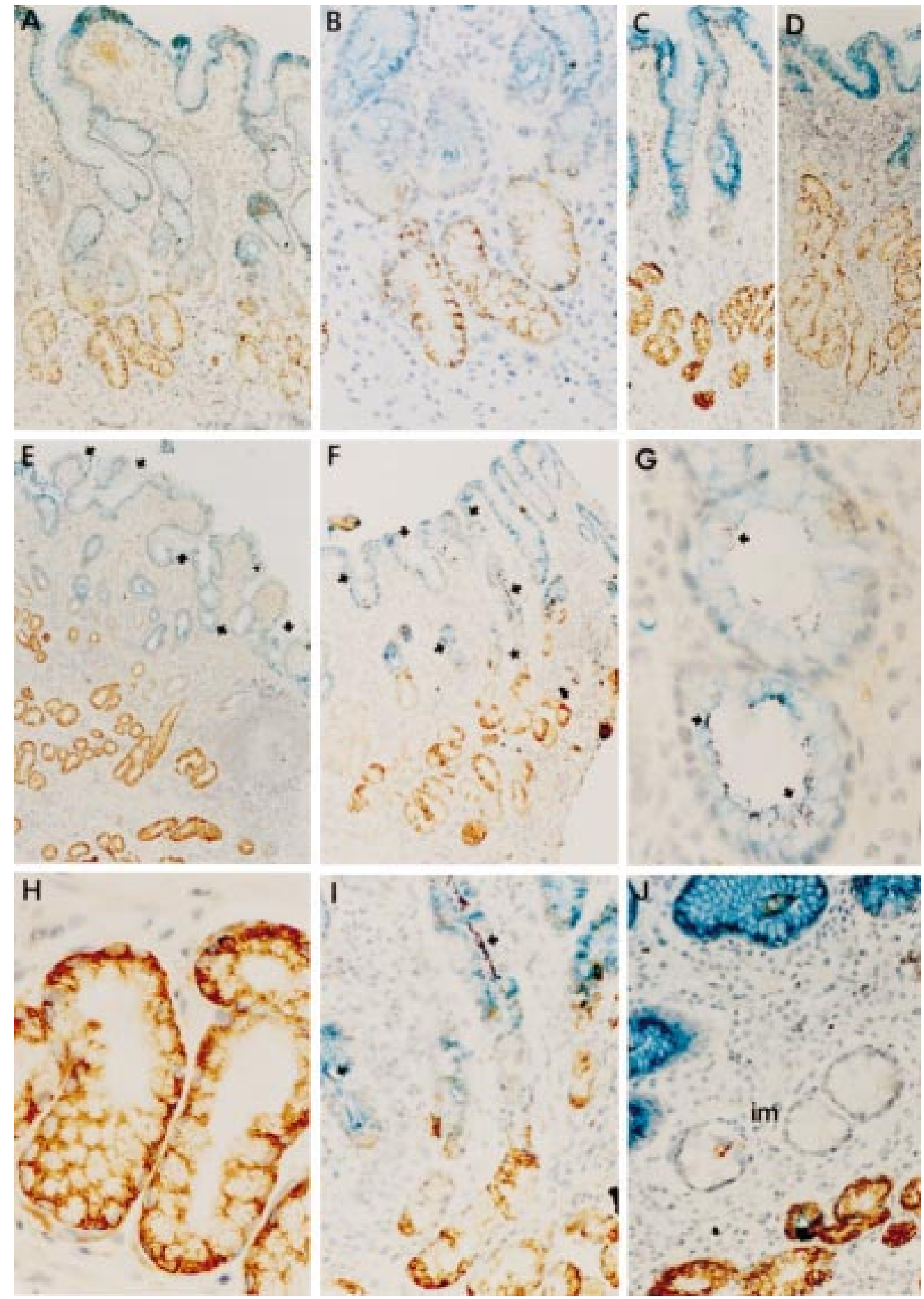

Figure 1 Immunohistochemical staining of sections of human stomach. All sections were immunohistochemically triple stained using antibodies against MUC5AC, MUC6, and H pylori. Detection of MUC5AC yielded a turquoise blue colour. MUC6 was detected using a DAB staining, staining MUC6 brown. Detection of $H$ pylori yielded a reddish purple staining. All sections were counterstained with haematoxylin. (A) Section from an individual without $H$ pylori infection. Note the complementary expression of MUC5AC and MUC6 within the epithelium. There is some yellow/orange staining in the mucosa. This is caused by erythrocytes that appear yellow/orange in this particular quadruple staining. (B) Higher magnification of A showing the transition zone of MUC5AC and MUC6 expression. (C) Distribution of MUC5AC and MUC6 along the pit-gland axis in a $H$ pylori negative patient. (D) A H pylori positive patient at the same

magnification as $C$ (the bacteria cannot be discerned at this magnification in this patient). Notice in $C$ and $D$ that the glands have approximately the same length, but that the number of MUC6 expressing cells has increased, whereas the number of MUC5AC expressing cells has diminished. (E) and (F) Sections of H pylori positive patients, showing heavy infection of the mucus layer and epithelium. The star indicates a gland that is shown at higher magnification in panel $I$. $(G-I)$ Higher magnifications of sections from $H$ pylori positive patients. Notice in $E-I$ that the $H$ pylori bacteria

colocalise with MUC5AC and with MUC5AC producing cells, but not with MUC6. (7) Section of a H pylori negative patient (after successful eradication of the bacterium), showing a focal area of intestinal metaplasia (im). Notice that the areas of intestinal metaplasia contain characteristic "intestinal type" goblet cells, but stained neither for MUC5AC nor MUC6. Arrows in E-G and I indicate purple stained, clustered $H$ pylori bacteria. In all patients the detection of $H$ pylori in the sections was in accordance with the culturing of the bacterium and routine histology using $H \mathcal{E} E$ staining. Original magnification $\times 62.5(A) ; \times 125(B) ; \times 62.5(C) ; \times 62.5(D) ; \times 31(E) ; \times 31(F) ; \times 250(G) ; \times 250(H) ; \times 50(I) ; \times$ $125(7)$. 
bacteria against the brown background of $\mathrm{DAB}$ stained MUC6.

In two patients we found focal areas of intestinal metaplasia. $H$ pylori was absent in these areas. It has previously been shown that areas of intestinal metaplasia show abundant expression of MUC2 and MUC3, the predominant intestinal mucins, and not MUC5AC or MUC6. ${ }^{25}$ As expected, we did not detect MUC5AC or MUC6 expression in these cells (fig 1J). We did, however, detect endogenous alkaline phosphatase activity on the brush border of these cells as typical for intestinal cells (data not shown).

\section{Discussion}

The mechanism underlying the tissue specificity of bacterial adhesion is poorly understood. As this host cell type dependent colonisation is the first step in the infectious process for most bacteria, it is important to elucidate the underlying mechanisms. In general, the mucous gel of the gastrointestinal tract is thought to be an important barrier in the cytoprotection against pathogenic organisms. In recent years however, it has become increasingly clear that a range of epithelial pathogens can use mucin, its most important structural component, to colonise this mucus barrier. However, many different mucins are expressed along the gastrointestinal tract, and we now show for the first time that a bacterium preferentially associates with one of these mucins.

The bacterium $H$ pylori is adapted to an environment of gastric mucus. In the duodenum, gastric metaplasia is very likely a prerequisite for the presence of the bacterium, ${ }^{33-35}$ and reports exist of $H$ pylori colonisation of gastric metaplastic tissue in Meckel's diverticula, ${ }^{36}{ }^{37}$ and even in the rectum. ${ }^{38}$ Although the prevalence of $H$ pylori colonisation at these distant sites of gastric metaplasia is low, these cases provide very interesting examples of the organism's specificity for gastric type epithelium. Additionally, areas of complete intestinal metaplasia in the stomach mucosa provide a hostile environment to $H$ pylori, as this bacterium is generally not detected in the mucus overlaying this epithelium, nor attached to these metaplastic epithelial cells.

From the above, it follows that the putative receptor responsible for $H$ pylori colonisation of the stomach should meet the following criteria: (i) present in mucus; (ii) specific for mucus produced by gastric type epithelium; (iii) not present in mucus overlaying areas of complete intestinal metaplasia; (iv) not present in the normal duodenum; and (v) present in areas of gastric metaplasia in the duodenum. A number of different receptors for $H$ pylori have been characterised in vitro (for review see Moran $^{39}$ ); importantly none of them meets the necessary criteria.

In the present study we focused on the distribution of two important gastric epithelial secretory gene products and their relation to the colonisation pattern of $H$ pylori. We hypothesised that MUC5AC could be a putative $H$ pylori receptor which could account for its colonisation pattern.
The secretory mucins MUC5AC and MUC6 are expressed in gastric epithelium. In studies investigating mucin expression in the gastrointestinal tract, these mucins have only been found in the stomach, and they are normally not expressed in the oesophagus or intestines. The cells of the superficial epithelium and the upper part of the gastric pits produce MUC5AC, whereas cells of the gastric glands and the lower part of the gastric pits express MUC6. The presence of MUC5AC in the superficial gastric epithelium makes it an attractive putative receptor for the tissue specific colonisation displayed by $\mathrm{H}$ pylori, as this bacterium is known to reside in this habitat.

We have shown, and to our knowledge for the first time, that expression of MUC5AC and MUC6 is complementary in the human stomach, and that gastric epithelial cells specifically express only one of both mucins. Interestingly, we also observed that $H$ pylori colonises the mucous gel layer overlaying cells producing MUC5AC and that the bacterium does not associate with cells producing MUC6. In all sections of the $34 \mathrm{H}$ pylori positive biopsy specimens examined, we noted a clear demarcation of the extent of $H$ pylori colonisation. This demarcation always corresponded to the sharply delineated transition between MUC5AC and MUC6 producing cell populations, even in densely colonised biopsy specimens. No clear difference in staining intensity of either MUC5AC or MUC6 was observed in any of the examined biopsy specimens, and the expression of both mucins was always found to be continuous. Importantly, we did not detect any MUC6 expression in superficial epithelial cells in these patients. This contrasts with earlier findings by Byrd et $a l,{ }^{40}$ who reported aberrant expression of MUC6 in the surface epithelium of 21 of $29 H$ pylori infected patients as well as focal areas where surface mucous cells did not stain with anti-MUC5AC antibodies. We showed that $H$ pylori can cause a shift in the relative sizes of the two gastric epithelial cell populations, expressing either MUC5AC or MUC6, as was observed in several $H$ pylori infected patients. Although we observed the same tendency of the gastric epithelium to produce increased numbers of MUC6 positive cells, as did Byrd et al, ${ }^{40}$ this never resulted in the expression of MUC6 in surface mucous cells. We have no explanation why our results are at variance with those of Byrd et al, other than differences in reagents and methodology to detect the mucins. Mechanistically, the observed change in the size of the MUC5AC and MUC6 producing cell populations by our group and Byrd's work could be caused by an altered turnover of one or both cell populations, or alternatively by a change in mucin expression.

The $H$ pylori binding receptor that has been characterised most carefully so far is Lewis B $\left(\mathrm{Le}^{\mathrm{b}}\right)$, a blood group antigen, and a terminal carbohydrate chain on glycoproteins and glycolipids. The affinity of $H$ pylori towards this carbohydrate was shown in an in situ adherence assay. ${ }^{41}$ In this assay fresh $H$ pylori adhered 
to fixed sections of human gastric tissue. Both soluble $\mathrm{Le}^{\mathrm{b}}$ and a monoclonal antibody to $\mathrm{Le}^{\mathrm{b}}$ interfered with this adhesion. The bacterial adhesin responsible for $\mathrm{Le}^{\mathrm{b}}$ antigen binding, BabA, has recently been identified. ${ }^{42}$ Although a pathophysiological role remains to be shown for infection of the human stomach, the BabA$\mathrm{Le}^{\mathrm{b}}$ interaction may be an important factor in the outcome of infection, as it increased the severity of gastritis in transgenic mice expressing human Le ${ }^{\mathrm{b}} .{ }^{12}$ Nevertheless, both transgenic animals and their controls were colonised. Importantly, $\mathrm{Le}^{\mathrm{b}}$ does not fulfil the five above mentioned criteria. Although $\mathrm{Le}^{\mathrm{b}}$ is present in gastric mucus, as a carbohydrate side chain of mucin, it is also expressed in the normal oesophagus, ${ }^{43}$ the duodenum, ${ }^{43}{ }^{44}$ and in areas of intestinal metaplasia. ${ }^{45}$ Indeed, it was shown that Le $\mathrm{L}^{\mathrm{b}}$ does not seem to play a critical role in the colonisation process of $H$ pylori in experiments in other model systems both in vitro and in vivo. ${ }^{47} 48$

It is not unimportant to place two technical aspects of our results in perspective. Firstly, we have found a strong colocalisation of $H$ pylori and MUC5AC. Yet we cannot exclude that the bacterium does not bind to MUC5AC directly. It is also possible that the bacterium associates with molecules that colocalise with MUC5AC. MUC5AC provides the structural framework for the gastric mucus layer. Therefore, it seems likely that the bacterium may try to get a foothold onto either the MUC5AC itself or to a molecule physically associated with MUC5AC. We are unable to discriminate between these possibilities. Secondly, our anti-MUC6 antibody only recognises the MUC6 precursor, and not the mature MUC6. Therefore, the bacteria could be associated with secretory MUC6 that is not recognised by the antiMUC6 antibody. The most important counterargument is that the $H$ pylori bacteria are not associated with the MUC6 producing cells, or located anywhere near the MUC6 producing cells in the lower part of the gastric glands, as one would expect when the bacteria associate to secretory MUC6.

In conclusion, we have provided the first evidence that MUC5AC constitutes an attractive candidate for the gastric mucus specific $H$ pylori receptor. In the present study we have shown that MUC5AC fulfils the necessary criteria in the human stomach: (i) MUC5AC is the structural component of the superficial gastric mucous gel layer; (ii) the expression of MUC5AC is specific for superficial gastric epithelial cells, MUC5AC is not expressed in normal duodenum or intestinal metaplasia of the duodenum; (iii) in the stomach, the colonisation pattern of $H$ pylori matches the area expression of MUC5AC $>99 \%$, the bacterium colocalises with extracellular MUC5AC as well as with the apical domain of MUC5AC producing epithelial cells, and not with MUC6. It remains to be shown whether MUC5AC is expressed in gastric metaplasia in the duodenum. This seems likely, however, as MUC5AC expression is highly specific for gastric epithelial cells. Finally, we did not observe any gross disturbances in the gastric mucin expression pattern. However, we did observe a shift in MUC5AC and MUC6 producing cell populations in some but not all of the $H$ pylori infected patients with a relative increase in MUC6 producing cells. The pathophysiological meaning of this finding remains unclear.

The authors would like to thank Dr C A Reis for the CLH2 antibody, Prof. D K Podolsky for the WE9 antibody, Dr C de Bolós for the MUC6.1 antibody, Prof. Y S Kim for the M3P antibody, and Dr B Appelmelk for the anti-H pylori antibody.

1 Mégraud F, Brassens-Rabbé MP, Denis F, et al. Seroepidemology of Campylobacter pylori infection in various populations. F Clin Microbiol 1989;27:1870-3.

2 Drumm B, Sherman P, Cutz E, et al. Association of Campylobacter pylori on the gastric mucosa with antral gastritis in children. N Engl f Med 1987;316:1557-61.

3 Peterson WL. H pylori and peptic ulcer disease. $N$ Engl $\mathcal{F}$ Med 1991;324:1043-8.

4 Parsonnet J, Friedman GD, Vandersteen DP, et al. H pylori infection and the risk of gastric carcinoma. $N$ Engl f Med 1991;325:1127-31.

5 Nomura A, Stemmermann GN, Chyou PH, et al. H pylori infection and gastric carcinoma among Japanese Americans in Hawaii. N Engl f Med 1991;325:1132-6.

6 Zucca E, Bertoni F, Roggero E, et al. Molecular analysis of the progression from $\mathrm{H}$ pylori-associated chronic gastritis to mucosa-associated lymphoid-tissue lymphoma. N Engl f Med 1998;338:804-9.

7 Hazell SL, Lee A, Brady L, et al. Campylobacter pyloridis and gastritis: association with intercellular spaces and adaptation to an environment of mucus as important factors in colonization of the gastric epithelium. F Infect Dis 1986;153:658-63.

8 Segal ED, Falkow S, Tompkins LS. H pylori attachment to gastric cells induces cytoskeletal rearrangements and tyrosine phosphorylation of host cell proteins. Proc Natl Acad Sci USA 1996;93:1259-64.

9 Segal ED, Lange C, Covacci A, et al. Induction of host signal transduction pathways by H pylori. Proc Natl Acad Sci USA 1997;94:7595-9.

10 Münzenmaier A, Lange C, Glocker E, et al. A secreted/shed product of $\mathrm{H}$ pylori activates transcription factor nuclear factor-кB. F Immunol 1997;159:6140-7.

11 Sharma SA, Tummuru MKR, Blaser MJ, et al. Activation of IL-8 gene expression by $\mathrm{H}$ pylori is regulated by transcription factor nuclear factor- $\mathrm{KB}$ in gastric epithelial cells. $\mathcal{F}$ Immunol 1998;160:2401-7.

12 Guruge JL, Falk PG, Lorenz RG, et al. Epithelial attachment alters the outcome of $\mathrm{H}$ pylori infection. Proc Natl Acad Sci USA 1998;95:3925-30.

13 Sherman PM, Boedeker EC. Pilus-mediated interactions of the Escherichia coli RDEC-1 with mucosal glycoproteins in the small intestine of rabbits. Gastroenterology 1987;93: 734-43.

14 Smith CJ, Kaper JB, Mack DR. Intestinal mucin inhibits adhesion of human enteropathogenic Escherichia coli to

15 Mack DR, Blain-Nelson PL. Disparate in vitro inhibition of adhesion of enteropathogenic Escherichia coli RDEC-1 by adhesion of enteropathogenic Escherichia coli RDEC- 1 by
mucins isolated from various regions of the intestinal tract. Pediatr Res 1995;37:75-80.

16 Kenny B, De Vinney R, Stein M, et al. Enteropathogenic E. coli (EPEC) transfers its receptor for intimate adherence into mammalian cells. Cell 1997;91:511-20.

17 Tzouvelekis LS, Mentis AF, Makris AM, et al. In vitro binding of $\mathrm{H}$ pylori to human gastric mucin. Infect Immun 1991; 59:4252-4.

18 Strous GJ, Dekker J. Mucin-type glycoproteins. Crit Rev Biochem Mol Biol 1992;27:57-92.

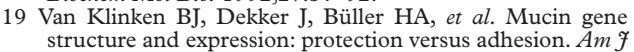
Physiol 1995;269:G613-27.

20 Bobek LA, Tsai A, Biesbrock AR, et al. Molecular cloning, sequence and specificity of expression of the gene encoding the low molecular weight human

21 Van Klinken BJ, Dekker J, Van Gool SA, et al. MUC5B is the predominant mucin in human gallbladder and is also the predominant mucin in human gallbladder and is also expressed in a subset.

22 Tytgat KMAJ, Büller HA, Opdam FJM, et al. Biosynthesis of human colonic mucin: MUC2 is the prominent secretory mucin. Gastroenterology 1994;107:1352-63.

23 Ho SB, Niehans GA, Lyftogt PS, et al. Heterogeneity of mucin gene expression in normal and neoplastic tissues. Cancer Res 1993;53:641-51.

24 Ho SB, Roberton AM, Shekels LL, et al. Expression cloning of gastric mucin complementary DNA and localization of mucin gene expression. Gastroenterology 1995;109:735-47.

25 Ho SB, Shekels LL, Toribara NW, et al. Mucin gene expression in normal, preneoplastic, and neoplastic human gastric epithelium. Cancer Res 1995;55:2681-90.

26 De Bolós C, Garrido M, Real FX. MUC6 apomucin shows a distinct normal tissue distribution that correlates with Lewis antigen expression in the human stomach. GastroenLewis antigen expression in
terology 1995;109:723-34.

27 Dixon MF, Genta RM, Yardley JH, et al. Classification and grading of gastritis. Am $\mathcal{F}$ Surg Pathol 1996;20:1161-81. 
28 Bara J, Chastre E, Mahiou J, et al. Gastric M1 mucin, an early oncofetal marker of colon carcinogenesis, is encoded 5:767-73

29 Dekker J, Aelmans PH, Strous GJ. The oligomeric structure of rat and human gastric mucins. Biochem f 1991;277:4237.

30 Reis CA, David L, Nielsen PA, et al. Immunohistochemical study of MUC5AC using a novel monoclonal antibody. In f Cancer 1997;74:112-21.

31 Podolsky DK, Fournier DA, Lynch KE. Development of anti-human colonic mucin monoclonal antibodies. Characterization of multiple colonic mucin species. 7 Clin Invest 1986;77:1251-62.

32 Appelmelk BJ, Simoons-Smit I, Negrini R, et al. Potential role of molecular mimicry between $\mathrm{H}$ pylori lypopolysaccharide and host Lewis blood group antigens in autoimmunity. Infect Immun 1996;64:2031-40.

33 Carrick J, Lee A, Hazell S, et al. Campylobacter pylori, duodenal ulcer, and gastric metaplasia: a possible role of functional heterotopic tissue in ulcerogenesis. Gut 1989;30: tional

34 Steer HW. Surface morphology of the gastroduodenal mucosa in duodenal ulceration. Gut 1984;25:1203-10.

35 Wyatt JI, Rathbone BJ, Dixon MF, et al. Campylobacter pyloridis and acid induced gastric metaplasia in the pathogenesis of duodenitis. $\mathcal{F}$ Clin Pathol 1987;40:841-8.

36 Morris A, Nicholson G, Zwi J, et al. Campylobacter pylori infection in Meckel's diverticula containing gastric mucosa. Gut 1989;30:1233-5.

37 De Cothi G, Newbold KM, Connor HJ. Campylobacterlike organisms and heterotopic gastric mucosa in Meckel's diverticula. F Clin Pathol 1989;42:132-4.

38 Dye KR, Marshall BJ, Frierson HF, et al. Campylobacter pylori colonizing heterotopic gastric tissue in the rectum. Am $f$ Clin Pathol 1990;93:144-7.
39 Moran AP. Cell surface characteristics of $\mathrm{H}$ pylori. FEMS Immunol Med Microbiol 1995;10:271-80.

40 . gyrd JC, Yan P, Sternberg L, et al. Abberant expression of
gland-type gastric mucin in the surface epithelium of $\mathrm{H}$ gland-type gastric mucin in the surface epithelium of $\mathrm{H}$

pylori-infected patients. Gastroenterology $1997 ; 113: 455-64$.
41 Boren T, Falk P, Roth KA, et al. Attachment of $\mathrm{H}$ pylori to human gastric epithelium mediated by blood group antigens. Science 1993;262:1892-5.

42 Ilver D, Arnqvist A, Ogren J, et al. $\mathrm{H}$ pylori adhesin binding fucosylated histo-blood group antigens revealed by retagging. Science 1998;279:373-7.

43 Davidson JS, Triadafilopoulos G. Blood group-related antigen expression in normal and metaplastic human upper gastrointestinal mucosa. Gastroenterology 1992;103:155261.

44 Mollicone R, Bara J, Le Pendu J, et al. Immunohistologic pattern of type 1 (Lea, Leb) and type $2(\mathrm{X}, \mathrm{Y}, \mathrm{H})$ blood group-related antigens in the human pyloric and duodenal mucosa. Lab Invest 1985;53:219-27.

45 Murata K, Egami H, Shibata Y, et al. Expression of blood group-related antigens, ABH, Lewis ${ }^{\mathrm{a}}$, Lewis ${ }^{\mathrm{b}}$, Lewis ${ }^{\mathrm{x}}$, group-related antigens, ABH, Lewis ${ }^{\text {a }}$ Lewis ${ }^{y}$, LA Lewis ${ }^{x}$, mewis, CA19-9 and CSLEX1 in early cancer, intestinal metaplasia, and uninvolved

46 Kobayashi K, Sakamoto J, Kito T, et al. Lewis blood grouprelated antigen expression in normal gastric epithelium, intestinal metaplasia, gastric adenoma and gastric carcinoma. Am f Gastroenterol 1993;88:919-24.

47 Oberhuber G, Kranz A, Dejaco C, et al. Blood groups Lewis $^{\mathrm{b}}$ and ABH expression in gastric mucosa: lack of inter-relation with $\mathrm{H}$ pylori colonization and occurrence of gastric MALT lymphoma. Gut 1997;41:37-42.

48 Clyne M, Drumm B. Absence of effect of Lewis A and Lewis B expression on adherence of $\mathrm{H}$ pylori to human gastric cells. Gastroenterology 1997;113:72-80. 